\title{
La nouvelle loi sur les épidémies mérite un oui clair le 22 septembre 2013
}

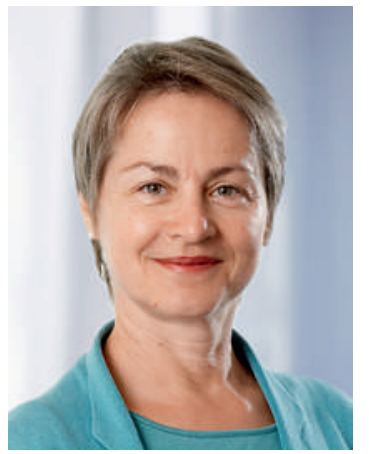

Vous souvenez-vous du SRAS? Fin 2002, un virus inconnu a marqué l'actualité. Il s'est propagé des campagnes chinoises au monde entier à la vitesse de l'éclair. Le coronavirus, qui ne touchait jusqu'alors que les animaux, a trouvé en l'homme un hôte potentiel, entraînant ainsi une transmission d'humain à humain.

Pourtant, la terrible épidémie tant redoutée ne s'est finalement pas déclarée et les quelque 900 morts dans le monde ont été largement inférieurs au nombre de décès annuels dus à la «traditionnelle» grippe saisonnière. Mais la crise du SRAS a mis en évidence des dysfonctionnements, notamment dans la manière dont les médias ont relayé le danger qui ne correspondait pas aux risques réels, avec en corollaire une méfiance accrue de la population face aux annonces de catastrophes.

Cela se reflète également dans la votation sur la révision de la loi sur les épidémies soumise à votation le 22 septembre prochain. Un des ténors des groupes référendaires évoque «la peur d'une pandémie régulièrement alimentée par les médias» qui ne saurait être une raison d'«accorder à une autorité étrangère un pouvoir totalitaire sur nous».

\section{Attendre une situation de crise pour tout d'abord déterminer qui fait quoi et quand risque de faire perdre un temps précieux.}

De quoi s'agit-il précisément? La loi en vigueur qui date de 1970 règle la lutte contre les maladies transmissibles de l'homme et confère à la Confédération et aux cantons la compétence de prendre des mesures visant à protéger la population. La crise du SRAS a souligné le danger que représentaient des mesures rendues inefficaces par un manque de clarté dans l'attribution des compétences. Attendre une situation de crise pour déterminer qui fait quoi et quand risque de faire perdre un temps précieux pour endiguer une épidémie réellement dangereuse. Par ailleurs, toutes les épidémies ne donnent pas lieu à une situation dangereuse et exceptionnelle. Ces prochaines années, il faudra plutôt régulièrement faire face à de nouveaux virus présentant un sérieux danger sans que la vie d'un grand nombre de personnes ne soit immédiatement menacée. La loi actuelle ne distingue que deux extrêmes, la situa- tion «normale» avec des apparitions épidémiques limitées à un territoire restreint, et la grande catastrophe, le scénario du pire, véritable menace pour la sécurité du pays. La nouvelle loi qui propose trois niveaux introduit la notion de «situation particulière», soit lorsqu'un risque spécifique menace la santé publique dans tout le pays. En matière d'épidémie, ce sera probablement la forme de menace la plus répandue ces prochaines années, et dans ce cas, ce sera au DFI d'assurer la responsabilité des opérations sans toucher au principe de répartition des compétences entre la Confédération et les cantons.

\section{Les virus ne s'arrêtent pas aux fron-}

tières. Une collaboration internationale efficace est donc nécessaire.

La vaccination obligatoire que les opposants à la révision de la loi taxent de «vaccination sous la contrainte» (Impfzwang) n'est pas nouvelle. Mais rappelons qu'aucune contrainte n'existe, ni dans la loi en vigueur ni dans la loi révisée. Personne n'a jamais été et ne sera jamais vacciné contre son gré. Jusqu'à présent, les cantons avaient déjà la possibilité de déclarer certaines vaccinations obligatoires. La nouvelle loi ne fait qu'exiger le respect de certains critères: définir les groupes à risques et limiter la vaccination obligatoire à ces groupes, pour autant qu'un danger sérieux soit établi. Dans certains services hospitaliers sensibles (par ex. néonatologie ou oncologie), il peut s'avérer judicieux de décréter la vaccination obligatoire pour le personnel dans le but de protéger les patientes et les patients. Chacun conserve néanmoins le choix de se faire vacciner ou non, mais sans vaccin, il ne pourra pas travailler dans un service sensible.

Enfin, le «pouvoir totalitaire d'une autorité étrangère » invoqué par les opposants relève d'une interprétation saugrenue. A l'instar de ce qu'a très bien montré le SRAS, les virus ne s'arrêtent pas aux frontières. Une collaboration internationale efficace est donc nécessaire. En outre, la nouvelle loi apporte de meilleures garanties en termes de protection des données par rapport à la version précédente.

La révision est adéquate et raisonnable, elle ne poursuit qu'un seul but, celui de protéger la population contre les maladies transmissibles. Dès lors la nouvelle loi sur les épidémies mérite un oui clair!

Dr Christine Romann, membre du Comité central de la FMH, responsable du domaine Promotion de la santé et prévention

\section{www.lep-oui.ch | www.lep-si.ch | www.jazumepg.ch}

